\title{
Simulasi Numerik Penambahan Slot Per Daun Terhadap Kekuatan Static Kendaraan Niaga
}

\author{
Agung Supriyanto ${ }^{1}$, Muhammad Vendy Hermawan ${ }^{1}$ \\ ${ }^{1}$ Sekolah Tinggi Teknologi Warga Surakarta \\ Jalan Raya Solo-Baki Km. 2, Kwarasan, Solo Baru, Sukoharjo \\ E-mail: agungatw@yahoo.com
}

\begin{abstract}
Commercial vehicles are a mode of transportation that plays an important role of the nation economy, so it is necessary to pay attention to their effectiveness and efficiency factors. Commercial vehicles have high effectiveness if they are able to send as many goods as possible, but the durability of vehicle components must be considered. One way to increase vehicle load capacity is by adding more slots leaf spring. This study aims to determine the effect of adding slot of leaf spring to the static strength of the rear suspension of Mitsubishi FE 71110 Ps. This study discusses the static strength of three types of leaf spring arrangement, they are original leaf spring arrangement, the addition of a $700 \mathrm{~mm}$ spring slot and an additional $1000 \mathrm{~mm}$ spring slot. The research was conducted by creating 3-dimensional design drawings and simulating static analysis using SolidWork software. The data sought are the stress and strain values for each variation. The result is the maximum stress value of the original leaf spring arrangement of $14.58 \times 107 \mathrm{~N} / \mathrm{m}^{2}$, an additional slot of $700 \mathrm{~mm} 21.80 \times 107 \mathrm{~N} / \mathrm{m}^{2}$, and an additional slot of $1,000 \mathrm{~mm} 24.93 \times 107 \mathrm{~N} / \mathrm{m}^{2}$.
\end{abstract}

Keywords: Leaf Spring, Simulation, Static strength, Stress, Strain,

\begin{abstract}
Abstrak
Kendaraan niaga merupakan moda transportasi yang berperan penting dalam roda perekonomian, sehingga perlu untuk memperhatikan faktor efektifitas dan efisiensinya. Kendaraan niaga memiliki efektifitas yang tinggi jika mampu mengirim barang sebanyak mungkin, tetapi faktor keawetan komponen kendaraan harus tetap diperhatikan. Salah satu cara meningkatan kemampuan daya muat kendaraan adalah dengan menambah slot per daun. Penelitian ini bertujuan untuk mengetahui pengaruh penambahan slot per terhadap kekuatan static per daun suspensi belakang truk Mitsubishi FE 71 110 Ps. Penelitian ini membahas kekuatan static pada tiga jenis susunan per daun, yaitu susunan per daun original, penambahan slot $700 \mathrm{~mm}$ dan penambahan slot $1000 \mathrm{~mm}$. Penelitian dilakukan dengan membuat gambar desain 3-dimensi dan melakukan simulasi analisis statik menggunakan software SolidWork. Data yang dicari adalah nilai tegangan dan regangan setiap variasi. Hasilnya adalah nilai tegangan maksimum susunan pegas daun original $14,58 \times 10^{7} \mathrm{~N} / \mathrm{m}^{2}$, penambahan slot $100 \mathrm{~mm} 21,80 \times 10^{7} \mathrm{~N} / \mathrm{m}^{2}$, dan penambahan slot $1.000 \mathrm{~mm} 24,93 \times 10^{7} \mathrm{~N} / \mathrm{m}^{2}$.
\end{abstract}

Kata kunci : Pegas daun, Simulasi, Kekuatan statik, Tegangan, Regangan,

\section{Pendahuluan}

Kendaraan Niaga merupakan semua kendaraan bermotor yang digunakan untuk mengangkut manusia atau barang. Truk merupakan salah satu wujud kendaraan niaga yang sering digunakan untuk mobilitas barang niaga. Kendaraan jenis ini digunakan sebagai kendaraan komersial, dimana semakin banyak barang yang mampu dimuat tetntunya akan semakin banyak pula nilai ekonomi yang diperoleh. Pelaku usaha ekspedisi truk biasanya melakukan modifikasi pada bagian suspensi untuk meningkatkan kekuatan struktur understeel truk. Melakukan penambahan slot pegas daun adalah salah satu cara yang dapat dilakukan untuk memperkuat struktur suspensi kendaraan.

Pegas daun berfungsi sebagai peredam getaran yang dihasilkan oleh roda, sehingga getaran tidak diteruskan ke bagian kabin [1]. Pegas daun dapat menerima beban lebih besar bila jika dibandingkan dengan pegas lainnya seperti pegas torsi dan pegas koil [2]. Beban dan tekanan yang diterima pegas daun akan berbeda- 
beda dalam setiap kondisi, hal ini akan menimbulkan tegangan dan regangan yang berbeda pula. Semakin tinggi tekanan kerja, tegangan pada struktur pegas daun akan meningkat [3]. Material pegas daun menggunakan baja SUP 9 dengan perlakuan panas [4]. Peningkatan kekuatan material pegas daun dengan perlakuan panas seperti quenching dan anealing terbukti mampu meningkatkan kekuatan struktur [5], [4].

Penelitian berbasis analisis menggunakan metode elemen hingga sudah banyak dilakukan. Di bidang otomotif, penelitian menggunakan perangkat lunak berbasis metode elemen hingga tentang pengaruh perbedaan material piston terhadap unjuk kerja piston pernah dilakukan. Hasil penelitian tersebut, material AlSi forged memiliki performa yang lebih baik jika dibandingkan dengan AlSi Casting [6]. Di bidang pertambangan, penelitian tentang analisis statik yang terjadi pada komponen point ripper dilakukan untuk mengetahui nilai konsentrasi tegangan di beberapa titik [7], [8].

Penggunaan perangkat lunak juga dapat dilakukan untuk menganalisis kekuatan pegas daun [9]. Simulasi kekuatan pegas daun dengan variasi material penyusun mild steel dan komposit karbon dihasilkan bahwa performa komposit karbon tidak jauh berbeda dengan mild steel [10]. Simulasi kekuatan pegas daun dengan material FRP, Titanium Alloy, Super Bainite dan Structural Steel diperoleh hasil bahwa material FRP memiliki kekuatan tertinggi dan berat paling ringan [11]. Upaya efisiensi material pegas daun dapat dilakukan dengan membuat alur grooving pada slot pegas daun. Dalam sebuah penelitian didapatkan bahwa penambahan 1 alur grooving slot pegas memiliki nilai tegangan dan displacement yang lebih kecil dibanding dengan versi original [12]. Penggunaan material komposit juga dapat mereduksi tegangan dan massa pegas daun [13].

Material yang sering digunakan dalam pembuatan pegas daun adalah baja SUP 9 [14]. Pegas daun pada kendaraan niaga berjenis Truk Mitsubishi Canter FE $71 \quad 110$ Ps juga menggunakan material tersebut karena ketangguhannya yang sudah teruji.

Tujuan penelitian ini adalah untuk mengevaluasi penambahan slot pegas daun pada kendaraan niaga berjenis truk. Penelitian dilakukan pada suspensi pegas daun bagian belakang. Fokus penelitian adalah pengaruh penambahan slot per daun $700 \mathrm{~mm}$ dan $1000 \mathrm{~mm}$ terhadap nilai tegangan dan regangan penyusun pegas daun. Data diperoleh dengan melakukan simulasi menggunakan perangkat lunak SolidWork.

\section{Methodologi}

Objek penelitian adalah komponen pegas daun truk Mitsubishi Canter FE 71 110 Ps. Penelitian dimulai dengan melakukan pengukuran pegas daun dan dilanjutkan membuat desain 3-Dimensi menggunakan perangkat lunak SolidWork. Parameter penelitian meliputi sifat material baja SUP 9 sebagai penyusun pegas daun, besar beban yang diterima oleh setiap pegas daun dan kondisi batas statis simulasi. Adapun diagram alir penelitian ditampilkan pada Gambar 1.

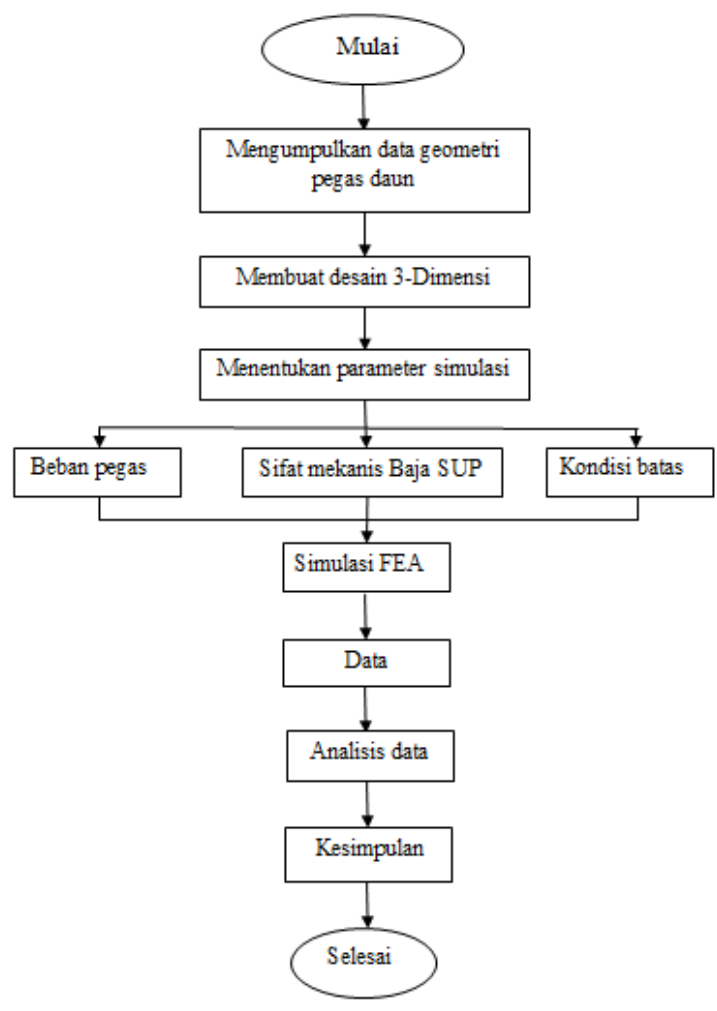

Gambar 1. Diagram alir penelitian

Desain 3-dimensi sebagai objek penelitian dibuat dalam 3 variasi susunan pegas daun, yaitu versi original, dengan penambahan slot pegas panjang $700 \mathrm{~mm}$ dan penambahan slot pegas panjang $1000 \mathrm{~mm}$.

\subsection{Desain 3-Dimensi Pegas Daun}

Pembuatan desain 3-dimensi diawali dengan melakukan pengukuran dimensi komponen asli. Selanjutnya, diperoleh data geometri yang digunakan untuk membuat desain 3-dimensi menggunakan perangkat lunak. Tampilan desain 3-dimensi pegas daun ditampilkan pada Gambar 2. Ukuran pegas daun disajikan pada Gambar 3 dan Tabel 1. 


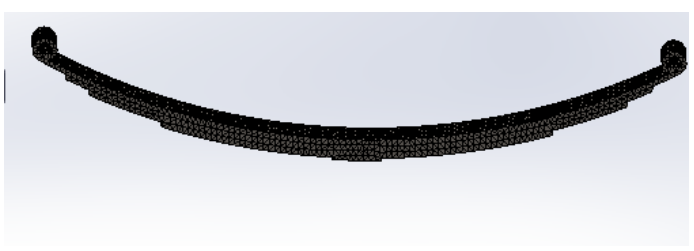

Gambar 2. Desain 3-dimensi pegas daun

Ukuran mesh yang digunakan adalah $5 \mathrm{~mm}$ dan berbentuk tetrahedon.

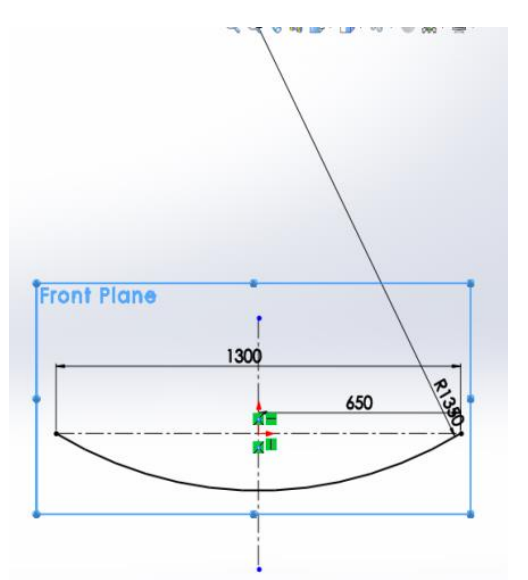

Gambar 3. Ukuran radius lengkungan pegas daun

Gambar 3 menampilkan ukuran radius kelengkungan pegas daun pertama. Pegas daun pertama berada di paling atas dalam susunan suspensi pegas daun. Suspensi original truk ............ memiliki 4 slot pegas yang tersusun urut dari yang terpanjang hingga terpendek. Adapun data ukuran pegas daun original ditampilkan pada Tabel 1 .

Tabel 1.

Ukuran pegas daun original

\begin{tabular}{ccc}
\hline Urutan Part & Panjang $(\mathrm{mm})$ & Tebal $(\mathrm{mm})$ \\
\hline Pegas 1 & 1300 & 12 \\
Pegas 2 & 1200 & 12 \\
Pegas 3 & 1100 & 12 \\
Pegas 4 & 800 & 12 \\
\hline
\end{tabular}

Penelitian ini membandingkan kekuatan pegas daun original dengan pegas daun yang dilakukan penambahan slot pegas $1000 \mathrm{~mm}$ dan $700 \mathrm{~mm}$. Adapun urutan susunan serta ukuran pegas daun dengan penambahan slot pegas 700 mm (modifikasi 1) dan $1000 \mathrm{~mm}$ (modifikasi 2) ditampilkan pada Tabel 2 dan 3.

Tabel 2.

Urutan susunan dan ukuran pegas daun modifikasi 1

\begin{tabular}{ccc}
\hline Urutan Part & Panjang $(\mathrm{mm})$ & Tebal $(\mathrm{mm})$ \\
\hline Pegas 1 & 1300 & 12 \\
Pegas 2 & 1200 & 12 \\
Pegas 3 & 1100 & 12 \\
\hline
\end{tabular}

\begin{tabular}{ccc}
\hline Pegas 4 & 800 & 12 \\
Pegas tambahan & 700 & 12 \\
\hline
\end{tabular}

Tabel 3.

Urutan susunan dan ukuran pegas daun modifikasi 2

\begin{tabular}{ccc}
\hline Urutan Part & Panjang $(\mathrm{mm})$ & Tebal $(\mathrm{mm})$ \\
\hline Pegas 1 & 1300 & 12 \\
Pegas 2 & 1200 & 12 \\
Pegas 3 & 1100 & 12 \\
Pegas tambahan & 1000 & 12 \\
Pegas 4 & 800 & 12 \\
\hline
\end{tabular}

\subsection{Baja SUP 9}

Baja SUP 9 adalah salah satu jenis baja yang khusus digunakan dalam pembuatan pegas daun, pegas koil dan torsion bar [15]. Komposisi kimia material baja SUP 9 terdiri dari $0,52-0,60 \% \mathrm{C}$; 0,65-0,95\% Mn; 0,4\% P; 0,15-0,35\% Si; 0,65$0,95 \%$ Cr dan 0,35\% S [16]. Sifat mekanis Baja SUP 9 disajikan pada Tabel 4. Sifat mekanis ini menjadi masukan parameter penelitian dalam simulasi desain 3-dimensi pegas daun [17].

Tabel 4.

Sifat mekanis Baja SUP 9

\begin{tabular}{cr}
\hline Sifat mekanis & \multicolumn{1}{c}{ Nilai } \\
\hline Density & $7.700 \mathrm{~kg} / \mathrm{m}^{2}$ \\
Yield Strength & $351,57 \mathrm{Mpa}$ \\
Modulus of Elascticity & $200.000 \mathrm{Mpa}$ \\
Poisson Ratio & 0,32 \\
Hardness & $78,83 \mathrm{HRB}$ \\
\hline
\end{tabular}

\subsection{Kondisi Batas Simulasi}

Kondisi batas simulasi digunakan untuk memberikan masukan parameter yang diperlukan dalam melakukan simulasi metode elemen hingga. Aplikasi peletakan parameter beban dan fix constrain ditampilkan pada Gambar 4 .

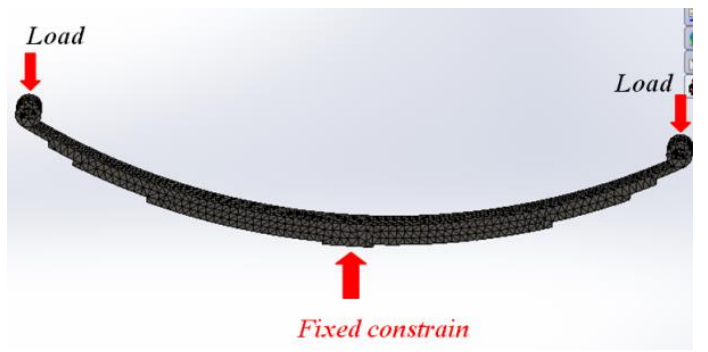

Gambar 4. Posisi beban dan fix constrain pada simulasi

Beban yang dimaksud adalah massa total dari kendaraan kosong sebesar $2.500 \mathrm{~kg}$ ditambah dengan kapasitas maksimum daya muat kendaraan sebesar $7.500 \mathrm{~kg}$. Terdapat 4 pegas daun dalam setiap kendaraan, sehingga pemberian beban dalam simulasi sebesar 4.000 
Kg karena suspensi belakang menopang beban lebih besar dibandingkan suspensi depan.

\section{Hasil dan Pembahasan}

Pengujian dilakukan menggunakan program Analisa Statis dengan perangkat lunak SolidWork. Data yang diperoleh adalah nilai tegangan dan regangan maksimum pegas daun.

\subsection{Analisis Tegangan Pegas Daun}

Hasil simulasi menunjukan nilai tegangan yang berbeda pada semua variasi susunan pegas daun. Gambar 5, 6 dan 7 menampilkan distribusi tegangan yang terjadi pada susunan pegas daun original, modifikasi 1 dan modifikasi 2.

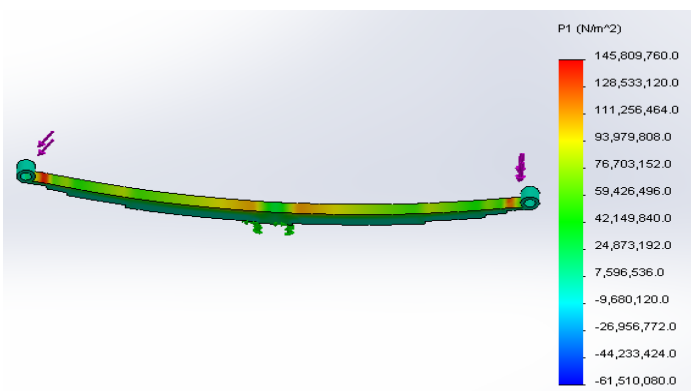

Gambar 5. Distribusi tegangan pegas daun original

Gambar 5 menunjukan bahwa nilai tegangan von mises maksimum pegas daun original ditunjukan dengan warna merah sebesar 14,580 $\times 10^{7} \mathrm{~N} / \mathrm{m}^{2}$. Tegangan terjadi pada area pangkal pegas daun paling atas (pegas 1 ).

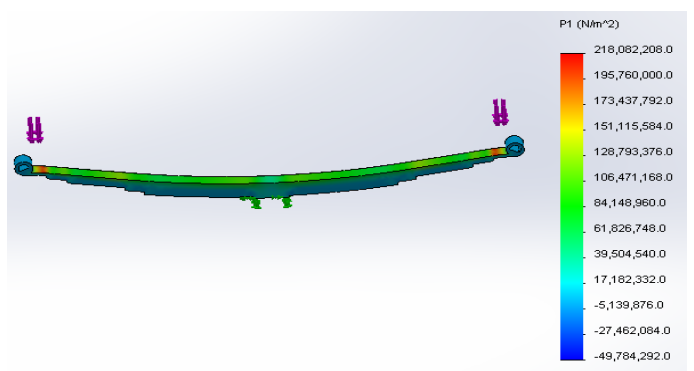

Gambar 6. Distribusi tegangan pegas daun modifikasi 1

Gambar 6 menunjukan distribusi tegangan pada pegas daun modifikasi 1. Modifikasi dilakukan dengan menambahkan slot pegas dengan panjang $700 \mathrm{~mm}$, tebal $12 \mathrm{~mm}$. Slot tambahan ini diletakan pada susunan paling bawah pegas daun (setelah pegas 4 ). Pegas daun modifikasi 1 memiliki nilai tegangan von mises maksimum sebesar $21,802 \times 10^{7} \mathrm{~N} / \mathrm{m}^{2}$. Tegangan maksimum terjadi pada area pangkal pegas 1 .

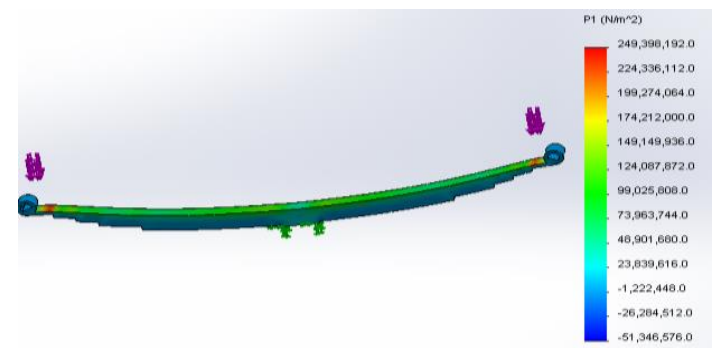

Gambar 7. Distribusi tegangan pegas daun modifikasi 2

Gambar 6 menampilkan distribusi tegangan pada pegas daun modifikasi 2. Penambahan slot pegas dengan panjang $1000 \mathrm{~mm}$, urutan susunan pegas dapat dilihat pada Tabel 2. Nilai tegangan von mises maksimum adalah $24,939 \times 10^{7} \mathrm{~N} / \mathrm{m}^{2}$. Tegangan maksimum masih terjadi di lokasi pangkal pegas 1 .

Hasil simulasi menunjukan bahwa pegas daun modifikasi 2 memiliki nilai tegangan maksimum terbesar. Sedangkan pegas daun original memiliki nilai tegangan maksimum terkecil. Penambahan slot pegas meningkatkan nilai tegangan yang terjadi.

Data distribusi tegangan pada setiap variasi simulasi menunjukan bahwa tegangan maksimum terjadi pada area yang sama. Area tersebut adalah pangkal pegas daun 1 dimana posisi nya paling dekat dengan tumpuan beban (rangka truk).

\subsection{Analisis Regangan Pegas Daun}

Analisis regangan diperlukan untuk mengetahui sifat elastis struktur pegas daun. Nilai regangan berbanding lurus terhadap tingkat elastisitas bahan [18]. Regangan maksimum dan distribusi regangan ditampilkan pada Gambar 8, 9 dan 10.

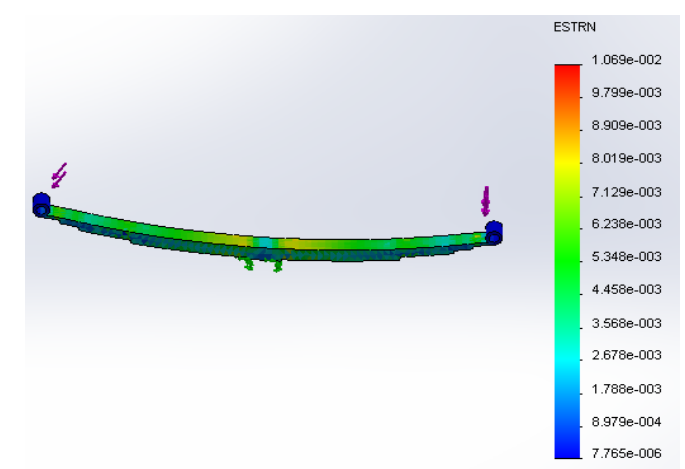

Gambar 8. Distribusi regangan pegas daun modifikasi 2

Gambar 8 menunjukan distribusi regangan yang terjadi pada pegas daun original. Konsentrasi regangan maksimum terjadi di area tengah pegas daun, yaitu di sekitar tumpuan pegas daun dengan as roda. Regangan 
maksimum pegas daun modifikasi 2 adalah sebesar $1,069 \times 10^{-2}$.

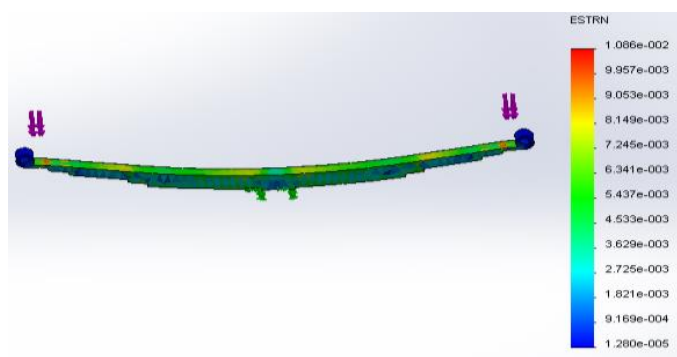

Gambar 9. Distribusi regangan pegas daun modifikasi 1

Gambar 9 menampilkan distribusi regangan pada pegas daun modifikasi 1 , yaitu penambahan slot pegas ukuran $700 \mathrm{~mm}$. Konsentrasi regangan maksimum terjadi pada area pangkal pegas, ditunjukan dengan warna merah pada desain simulasi. Hal ini disebabkan karena efek penambahan slot pegas panjang $700 \mathrm{~mm}$ meningkatkan struktur kekuatan di area tengah pegas daun saja, tetapi area pangkal pegas tidak terjadi peningkatan kekuatan. Nilai regangan maksimum yang terjadi adalah sebesar 1.086 $\mathrm{x} 10^{-2}$

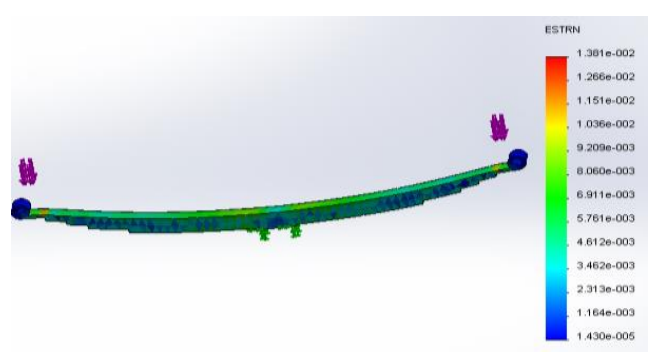

Gambar 10. Distribusi regangan pegas daun original

Gambar 10 menampilkan distribusi regangan pada pegas daun original, yaitu tanpa penambahan slot pegas. Konsentrasi regangan kritis terjadi tidak hanya pada satu area, tetapi lebih merata di area pangkal dan tengah pegas daun. Nilai regangan maksimum pegas daun original adalah sebesar $1.381 \times 10^{-2}$. Nilai regangan yang tinggi menunjukan bahwa struktur pegas daun memiliki sifat elastis yang tinggi. Hal ini berakibat, struktur tidak bisa menahan beban muatan yang berlebih.

\section{Simpulan}

Penambahan slot pegas berpengaruh terhadap peningkatan nilai tegangan dan regangan pegas daun. Penambahan slot pegas $700 \mathrm{~mm}$ mengakibatkan terjadinya konsentrasi tegangan kritis yang berfokus pada satu area, yaitu ujung pangkal pegas daun. Distribusi tegangan yang lebih merata terjadi pada Penambahan slot pegas $1000 \mathrm{~mm}$, dimana tegangan kritis terjadi di area tengah dan pangkal pegas. Nilai regangan paling rendah dan tegangan paling tinggi dimiliki oleh susunan pegas daun modifikasi 2. Ini memungkinkan bahwa penggunaan pegas daun dengan penambahan slot pegas $1000 \mathrm{~mm}$ akan meningkatkan kekuatan struktur suspensi yang lebih baik jika dibandingkan dengan susunan pegas original dan penambahan slot pegas 700 $\mathrm{mm}$.

\section{Daftar Pustaka}

[1] A. B. Permana and A. M. Sakti, "Studi Eksperimen Kekuatan Impact dan Bending Baja Karbon Pegas Daun AISI 1095 Pada Mobil Kijang Kapsul 7K-EFI Tahun 2000 Dengan Perlakuan Panas Tempering," JPTM Univ. Negeri Surabaya, vol. 09, no. 03, pp. 67-75, 2020.

[2] E. Saputra, R , Tyastomo, "Perbandingan kekerasan dan struktur mikro pegas daun yang mengalami proses heat treatment," Bina Tek., vol. 12, no. 2, pp. 185-193, 2016.

[3] I. Thamrin, "Analisa TeganganRegangan Struktur Pegas Daun Akibat Modifikasi Penekanan," J. Rekayasa Mesin, vol. 09, no. 1, pp. 18-22, 2009.

[4] M. S. Setiawan, I. Nur, "Meningkatkan Mutu Baja Sup 9 Pada Pegas Daun Dengan Proses Perlakuan Panas," Fis. Terap., vol. 9, pp. 36-44, 2008.

[5] P. I. Purboputro, "Peningkatan Kekakuan Pegas Daun Dengan Cara Quenching," Media Mesin Maj. Tek. Mesin, vol. 10, no. 1, pp. 15-21, 2017.

[6] M. V. Hermawan, A. D. Anggono, W. A. Siswanto, and T. W. B. Riyadi, "The influence of material properties to the stress distribution on piston, connecting rod and crankshaft of diesel engine," Int. J. Mech. Mechatronics Eng., vol. 19, no. 6, pp. 13-26, 2019.

[7] A. Supriyanto, M. V. Hermawan, and A. C. K, "Pemilihan Material Berdasarkan Tegangan dan Deformasi Pada Redesain Point Ripper Dozer D85E-SS-2," RAPI, vol. m, pp. 78-84, 2019.

[8] A. Supriyanto and R. Ardianto, "Pengaruh Redesain Point Ripper Dozer D85E-SS-2 Terhadap Tegangan dan 
Displacement Akibat Beban Horisontal.," pp. 85-91, 2019.

[9] K. S. Ashraff Ali, D. Joseph Manuel, M. Balamurugan, and M. Sangili Murugan, "Analysis of composite leaf spring using ANSYS software," Mater. Today Proc., no. Xxxx, 2020.

[10] B. Mallesh, B. Gupta, S. K. Kumar, and S. P. Jani, "Materials Today: Proceedings Modeling and analysis of leaf spring with different type of materials," Mater. Today Proc., no. xxxx, 2020.

[11] C. D. Bhatt, M. Nadarajan, R.Balaji, I. rohith, and A. Selokar, "Leaf spring model for heavy load vehicle using solid works and ANSYS analysis," Mater. Today Proc., no. xxxx, 2020.

[12] L. Lukman, A. D. Anggono, and S. Sarjito, "Desain Dan Optimisasi Sistem Suspensi Pegas Daun Pada Kendaraan Roda 3 Dengan Menggunakan Catia V5," Turbo J. Progr. Stud. Tek. Mesin, vol. 7, no. 1, 2018.

[13] S. Seralathan et al., "Finite element analysis of hybrid composite material based leaf spring at various load conditions," Mater. Today Proc., no. xxxx, 2020.
[14] M. Ibrahim and Purwantono, "Pengaruh Pemanasan Sebelum Pengelasan Terhadap Pengujian Face dan Root Bending Hasil Las SMAW Baja SUP 9," J. Multidiciplinary Res. Dev., pp. 230237, 2019.

[15] A. S. Umartono and S. Awali, "Analisa Kegagalan Proses Heat Treatment Baja Sup-9 Pada Pembuatan Pegas Daun," Wahana Tek., vol. 04, pp. 55-75, 2015.

[16] E. R. Permana, H. Akhmad, and A. Rasyid, "Studi Eksperimen Pengaruh Suhu Tempering Pada Baja Pegas JIS SUP 9 Terhadap Impact Edo Riyan Permana Akhmad Hafizh Ainur Rasyid," J. Tek. Mesin, vol. 06, no. 01, pp. 17-24, 2018.

[17] J. D. of M. E. William D. Callister and T. U. of Utah, Materials Science and Engineering, 7th ed., vol. 7. Utah, United state: John Wiley \& Son, inc, 2007.

[18] et al Rompas, "Pengaruh Pemanfaatan Abu Ampas Tebu Sebagai Substitusi Parsial Semen Dalam Campuran Beton Ditinjau Terhadap Kuat Tarik Lentur Dan Modulus Elastisitas," J. Sipil Statik, vol. 1, no. 2, pp. 82-89, 2013. 